\title{
Morphological and Genetic Characterization of Micropropagated Field Grown Plants of Aloe vera L.
}

\author{
Anusree Das, SK. Moquammel Haque ${ }^{1}$, Biswajit Ghosh ${ }^{1}$, \\ Krishnadas Nandagopal and Timir Baran Jha ${ }^{2 *}$
}

Department of Genetics, University of Calcutta, Kolkata-700019, India

Key words: Aloe vera, Fruit and fertile seed production, Genetic characterization, Somaclone

\begin{abstract}
A large scale shoot multiplication from apical meristem in Aloe vera L. was obtained on MS with $35.5 \mu \mathrm{M}$ BAP, $9.8 \mu \mathrm{M}$ IBA and $81.4 \mu \mathrm{M}$ adenine sulphate. Fifty micropropagated plants were successfully transferred to the field and maintained to attain reproductive phase. Field evaluation of micropropagated plants is important to assess predicted clonal fidelity. Exo-morphological evaluation of Aloe plants, identified three seed setting plants, designated as somaclones. Seeds were viable and germinated (70.58\%) in vitro. Although chromosome number and morphology of somaclones were identical with the donor plants their RAPD profiles and ITS-1 sequences were different from donor plant. This study reports Seed setting somaclones in Aloe vera, for the first time which may serve as new genetic resource for biotechnological improvement.
\end{abstract}

\section{Introduction}

Aloe vera $\mathrm{L}$. is an ancient perennial medicinal herb of Asphodelaceae. The plant is renowned for its leaf gel which has proven its efficacy against external burns, skin disorders (Nia et al. 2004), gastrointestinal malfunction (Grindlay et al. 1986, Shelton 1991) and prevents UV-B induced immune suppression of the skin (Strickland et al. 1994). This medicinal plant is also used as anti-cancer (Winters et al. 1981), anti-oxidant (Hu et al. 2003), anti-inflammatory (Davis et al. 1994), anti-diabetic agent (Davis et al. 1989). The leaf gel of $A$. vera is composed of a large number of nutritionally enriched compounds of which aloin, an anthraquinone glycoside, is identified as the most important bioactive compound.

*Author for correspondence: <tbjha2000@yahoo.co.in>. ${ }^{1}$ Department of Botany, RKMVC College, Rahara, Kolkata- 700118, India. 2PG Department of Botany, Barasat Govt. College, Barasat, Kolkata-700124, India. 
Although $A$. vera produces a large number of healthy bisexual flowers, it reproduces via vegetative propagation. Naturally producing viable seeds has been reported in a few species of Aloe, such as A. arborescens (Amoo et al. 2012), A. saponaria (Velasquez-Arenas and Imery-Buiza 2008). Conventionally, plant breeders recombine the desired genes from plant varieties and related species by sexual hybridization and develop new cultivars with the desirable traits. However, in case of $A$. vera sexual hybridization is not possible due to lack of fertile seed production.

Micropropagation technique offers great potential for plant improvement, if genetically uniform, quality plants can be regenerated in large numbers independent of seasonal and other environmental variables. Generation of micropropagated plants of $A$. vera through in vitro culture and their field transfer has been reported by many workers (Wenping et al. 2004, Liao 2004, Aggarwal and Barna 2004, Rathore et al. 2011), but very few of them have studied the long term evaluation of field grown micropropagated plants in this species, even though it is essential for commercial production. Tissue culture induces variation which can result in a range of genetically stable variation, useful in crop improvement (Larkin and Scowcroft 1981). The occurrence of somaclones has been reported in many in vitro regenerated plants (Jaljai et al. 2006, Minano 2009). Evaluation of clonal fidelity is vital parameter to test the in vitro grown plants for commercial use and trade. Chromosomal analysis coupled with DNA fingerprinting has emerged as most desirable genetic tools to study genetic variation among plants (Garcia-Mas et al. 2000, Chaudhuri et al. 2009).

We have focused on one certified cultivar of $A$. vera having high aloin content. We have standardized in vitro multiplication protocol of $A$. vera and transferred the micropropagated plants to the field (Das et al. 2010a). This report aims to study the exo-morphological characters, floral traits, cytological analysis and analysis of DNA fingerprinting profiles with RAPD marker and sequencing data of ITS-1 and 2 of nuclear ribosomal DNA of in vitro field grown and donor plants of Aloe vera.

\section{Material and Methods}

Plants of bitter cultivar of Aloe vera (AvS1) were collected from National Bureau of Plant Genetic Resources (NBPGR), Central Arid Zone Research Institute (CAZRI), Jodhpur, India and were maintained in the experimental garden. An efficient micropropagation protocol using shoot apical meristem was established involving the induction, multiplication and in vitro rooting of the regenerated shoots and their acclimatization under ex vitro conditions (Das et al. 2010a). The plantlets were successfully hardened and the plants were transferred to a larger 
field in the Ramkrishna Mission Vivekananda Centenary College, Rahara and maintained for further study.

Fifty tissue culture regenerated plants were selected randomly. Quantitative and qualitative morphological traits of those plants were studied in detail. Inflorescence characteristics were carefully recorded. Morphological traits of fruit and seeds were studied and recorded accordingly. Mature and immature seeds were placed in full and half strength MS and water soaked filter paper for in vivo and in vitro germination, respectively and percentages of seed germination under the different conditions were recorded.

Somatic chromosome analysis was carried out from the root tips of the tissue culture raised plants following EMA method and Giemsa staining according to the basic protocol of Fukui (1996) with modifications (Jha and Yamamoto 2012). Chromosome analysis was carried out following the standard protocol of (Sharma and Sharma 1980). Pollen viability was tested following Singh and Dhuria 1960 and the percentage of viable pollen grains was recorded.

Genomic DNA was isolated from leaf tissue following the method of Doyle and Doyle (1990) with minor modifications. One gm of fresh leaf tissue was grounded in liquid nitrogen and then transferred to $6 \mathrm{ml}$ of freshly prepared extraction buffer [100 mM Tris-HCl ( $\mathrm{pH} 8.0), 25 \mathrm{mM}$ EDTA, $1.5 \mathrm{M} \mathrm{NaCl}, 2 \%$ CTAB (W/V), $1 \%$ polyvinyl pyrrolidone (PVP), $\beta$-mercaptoethanol $(0.2 \%, \mathrm{v} / \mathrm{v})]$. Protein and cellular debris were removed by treating the homogenate with an equal volume of chloroform: isoamyl alcohol $(24: 1)$ and then centrifuged at $10,000 \mathrm{rpm}$ for $20 \mathrm{~min}$ at room temperature (RT) $\left(25 \pm 2^{\circ} \mathrm{C}\right)$. DNA precipitation step was carried out with $3 \mathrm{M}$ sodium acetate and chilled ethanol. The pellet obtained was dissolved in TE buffer (10 mM Tris-HCl, pH 8.0 and 1 mM EDTA). RNA contamination was removed by RNase A $(1 \mathrm{U} / \mu \mathrm{l})$ treatment. The quality of DNA was checked through $0.8 \%$ agarose gel analysis and the quantity was measured through a spectrophotometer.

Amplification of RAPD fragments were performed with RAPD decamer primers (Operon Technologies Inc., Alameda, CA) following the protocol of Williams et al. (1990) with minor modifications (Rathore et al. 2011). 2. The amplified fragments were visualized under UV light and documented using the gel documentation equipment (BioRad). The data were used to calculate similarity coefficient (Nei and Li 1979), and a dendrogram was constructed by UPGMA cluster analysis using the NTSYS program (2.1) to analyse the genetic relationship.

ITS1 and ITS2 regions of ribosomal DNA were independently amplified using primers (5'-TCCGTAGGTGAACCTGCGG-3') and (5'-GCTGCGTTCTT CATCGATGC-3') and (5'-GCATCGATGAAGAACGCAGC-3') and (5'-TCCTCC 
GCTTATTGATATGC-3') of White et al. (1990), respectively. PCR amplification parameters were 1 denaturation cycle of $3 \mathrm{~min}$ at $94^{\circ} \mathrm{C}$ followed by 35 cycles of 1 min at $94^{\circ} \mathrm{C}, 1 \mathrm{~min}$ at $55^{\circ} \mathrm{C}$ and $2.5 \mathrm{~min}$ at $72^{\circ} \mathrm{C}$ and a final extension at $72^{\circ} \mathrm{C}$ for 10 min. The PCR products were resolved in $1.5 \%$ agarose gel. Three hundred bp and $340 \mathrm{bp}$ fragments were obtained for each ITS1 and ITS2 regions, respectively. The PCR products were purified using PCR purification kit (QIAGEN) and sequenced using universal primers. All the sequences were subjected to Nucleotide BLAST and Clustal- $\Omega$ software-based analysis (Banerjee and Nandagopal 2009). Completed sequences were submitted to GENEBANK database of NCBI (Table 5).

The experiments were set up in a randomized design. Data were analyzed by ANOVA to detect significances between the mean values. Mean values differing significantly were compared using DMRT at a $5 \%$ level of confidence $(p=0.05)$. Variability of data has been expressed as the mean \pm standard error (SE).

\section{Results and Discussion}

Shoot apical meristems of the donor Aloe vera plant (Fig. 1a) were cultured in MS supplemented with 3\% sucrose. Shoot bud induction was found best in MS containing $35.5 \mu \mathrm{M}$ BAP, $9.8 \mu \mathrm{M}$ IBA and $81.4 \mu \mathrm{M}$ adenine sulphate (Fig. 1b). Multiplication of newly formed shoot buds was obtained in MS supplemented with $8.87 \mu \mathrm{M}$ BAP and $2.46 \mu \mathrm{M}$ IBA and $108.58 \mu \mathrm{M}$ adenine sulphate (Fig. 1c) (Das et al. 2010a). A large number of proliferated shoot buds were obtained within 4 weeks of the first subculture (Fig. 1d). Rooted plants (Fig. 1e) were hardened in the greenhouse and transferred to a large field for further growth (Fig. 1f). Micropropagated plants were acclimated in the field condition and they started flowering within one and a half year (Fig. 1g).

Regenerated plants attained a height of average $55.16 \pm 1.30 \sim 55.16 \mathrm{~cm}$ within 2-3 years (Table 1). The fleshy, thick $(2.22 \pm 0.33 \sim 2.22 \mathrm{~cm})$, lanceolate leaves were dark green in color and grow to $52.91 \pm 1.14 \mathrm{~cm}$ with $8.11 \pm 0.52 \mathrm{~cm}$ width at base (Table 1). The leaf margins were armed with conspicuous, stout spines. In contrast to the donor plants, the in vitro raised plants possessed red, curved spines showing a higher spine frequency i.e., 10 per $10 \mathrm{~cm}$ of length of leaf (Table 1) than that of the donor plant. Both the donor and in vitro raised plants slowly offset to form a clump. The in vitro raised plants produce average 9 suckers per plant per year which is higher than that of mother plants (Table 1).

Both the donor and in vitro raised plants flowered nearly at the same time of the year i.e., between September and December. Within one and half years, the field grown in vitro raised plants produced inflorescences which at maturity attained an average height of $156.6 \pm 9.81 \sim 156.6 \mathrm{~cm}$ (Table 2). In donor plants of 
AvS1, bright-orange flowers were observed on $160.2 \pm 4.30 \sim 160 \mathrm{~cm}$ long inflorescence axis bearing 1-4 shafts (Table 2). However, in vitro raised plants produced an average of $251.22 \pm 0.91 \sim 251$ numbers of orange flowers distributed in 10 lateral shafts of an intact inflorescence (Fig. 2a) (Table 2).

Table 1. Exo-morphological characteristics of Aloe vera.

\begin{tabular}{|c|c|c|c|}
\hline & Characters & $\begin{array}{l}\text { Donor plant } \\
(\text { Mean } \pm \text { SE) }\end{array}$ & $\begin{array}{l}\text { Tissue Culture } \\
\text { Regenerates (Mean } \pm \text { SE) }\end{array}$ \\
\hline \multirow{6}{*}{$\begin{array}{l}\text { Quantitative } \\
\text { traits }\end{array}$} & Plant height (cm) & $70.00 \pm 2.20^{\mathrm{a}}$ & $55.16 \pm 1.30^{\mathrm{b}}$ \\
\hline & Leaf thickness $(\mathrm{cm})$ & $2.48 \pm 0.31^{\mathrm{b}}$ & $2.22 \pm 0.33^{c}$ \\
\hline & Leaf width $(\mathrm{cm})$ & $10.25 \pm 0.44^{\mathrm{b}}$ & $8.11 \pm 0.52^{\mathrm{d}}$ \\
\hline & Leaf Length & $80.37 \pm 1.33^{c}$ & $52.91 \pm 1.14^{\mathrm{d}}$ \\
\hline & $\begin{array}{l}\text { Spine frequency } / 10 \mathrm{~cm} \\
\text { length of leaf }\end{array}$ & $6.0 \pm 0.11^{b}$ & $10.09 \pm 0.23^{b}$ \\
\hline & Number of suckers/plant & $5.01 \pm 0.41^{\mathrm{c}}$ & $9.00 \pm 0.22^{\mathrm{a}}$ \\
\hline \multirow{5}{*}{$\begin{array}{l}\text { Qualitative } \\
\text { traits }\end{array}$} & Leaf Shape & Lanceolate & Lanceolate \\
\hline & Leaf colour & Dark green & Dark green \\
\hline & Leaf Spots & $\begin{array}{l}\text { Elliptical, light green, } \\
\text { concentrated at the } \\
\text { base }\end{array}$ & $\begin{array}{l}\text { Elliptical, Light green } \\
\text { concentrated at the base, } \\
\text { more in number on } \\
\text { adaxial surface of lamina }\end{array}$ \\
\hline & Spine Colour & White with red tip & Red \\
\hline & Spine Nature & Stout, pointed & Curved, stout \\
\hline
\end{tabular}

Each value represents the mean \pm S.E. Mean values having different letters in superscript are significantly different from each other $(\mathrm{P} \leq 0.05)$ according to Duncan's Multiple Range Test (Wang et al. 2009)

Table 2. Characteristics of inflorescence of Aloe vera

\begin{tabular}{lll}
\hline Characters & Donor plant & $\begin{array}{l}\text { Tissue Culture } \\
\text { Regenerates }\end{array}$ \\
\hline $\begin{array}{l}\text { Number of inflorescence/plant/ } \\
\text { flowering season }\end{array}$ & $1.0 \pm 0.41^{\mathrm{a}}$ & $1.0 \pm 0.41^{\mathrm{a}}$ \\
Height of inflorescence (cm) & $160.2 \pm 4.30^{\mathrm{b}}$ & $156.6 \pm 9.81^{\mathrm{c}}$ \\
Number of shafts/inflorescence & $4.96 \pm 0.29^{\mathrm{d}}$ & $10.26 \pm 1.11^{\mathrm{d}}$ \\
Number of flowers on the main axis & $45.69 \pm 2.27^{\mathrm{e}}$ & $52.23 \pm 1.99^{\mathrm{e}}$ \\
Number of flowers in the lateral shafts & $32.33 \pm 1.59^{\mathrm{a}}$ & $203.11 \pm 0.66^{\mathrm{b}}$ \\
Total number of flowers/inflorescence & $89.22 \pm 2.10^{\mathrm{a}}$ & $251.22 \pm 0.91^{\mathrm{c}}$ \\
Duration(days) of flowering/inflorescence & $25.1 \pm 1.36^{\mathrm{b}}$ & $27.39 \pm 2.14^{\mathrm{d}}$ \\
Duration(days) of the inflorescence & $37.58 \pm 1.55^{\mathrm{c}}$ & $45.01 \pm 1.22^{\mathrm{c}}$ \\
\hline
\end{tabular}

Each value represents the mean \pm S.E. Mean values having different letters in superscript are significantly different from each other $(\mathrm{P} \leq 0.05)$ according to DMRT (Wang et al. 2009). 

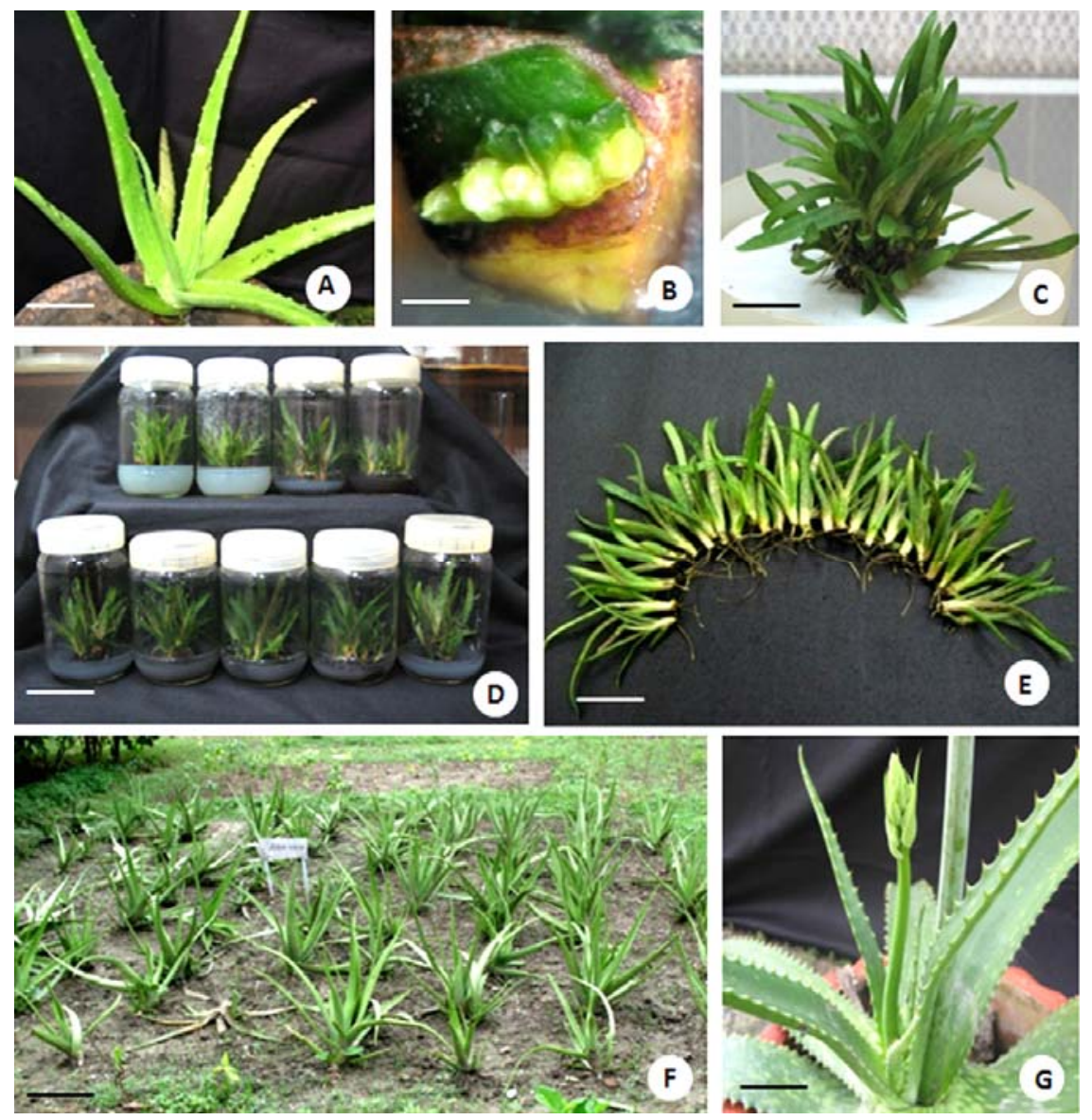

Fig. 1 Micropropagation and field transfer of in vitro grown plants of Aloe vera (a) The donor plant of Aloe vera. Bar $=8.0 \mathrm{~cm}$. (b) Initial induction of shoot buds. Bar $=0.5 \mathrm{~cm}$. (c) Multiplication of shoot buds. Bar $=0.5 \mathrm{~cm}$. (d) Large number of shootlets in the culture medium. Bar $=0.5 \mathrm{~cm}$. (e) Rooted shoots prior to hardening. Bar $=0.5 \mathrm{~cm}$. (f) Micropropagated plants growing in the field conditions. Bar $=0.5 \mathrm{~cm}(\mathrm{~g})$ Tissue culture raised field grown plant showing the production of inflorescence. $B a r=0.5 \mathrm{~cm}$.

At the end of the flowering season, one important observation was noted in 3 in vitro raised plants of AvS1 among the fifty studied. Flowers were found to convert into fruits in those 3 plants for three consecutive years (Fig. 2a,b,c). Simultaneous development of flowers and fruits were noted in the same flowering axis (Fig. 2d,e,f). Full bloom of flower and subsequent conversion of flowers to fruit and consequential maturation occurred within 6-7 weeks (Fig. $3 a, b, c)$. The average number of fruits per plant was $34.2 \pm 2.56 \sim 34$ and each pod was found to contain $12.6 \pm 1.44 \sim 12$ seeds in the first year (Table 3). In the second and third year, the number of fruits per inflorescence increased to $40.0 \pm 1.66 \sim 40$ 
and $42.00 \pm 1.56 \sim 42$, respectively (Table 3 ) but the number of seeds per fruit was found to remain constant. The size and weight of the mature fruit was $\simeq 21 \mathrm{~mm} \mathrm{x}$ $8 \mathrm{~mm}$ and $\simeq 90-95 \mathrm{mg}$, respectively and individual seeds weighed $\simeq 0.92 \pm 0.23$ $\mathrm{mg}$ in both the years (Fig. 3d). Field evaluation data of Aloe vera (AvS1) revealed
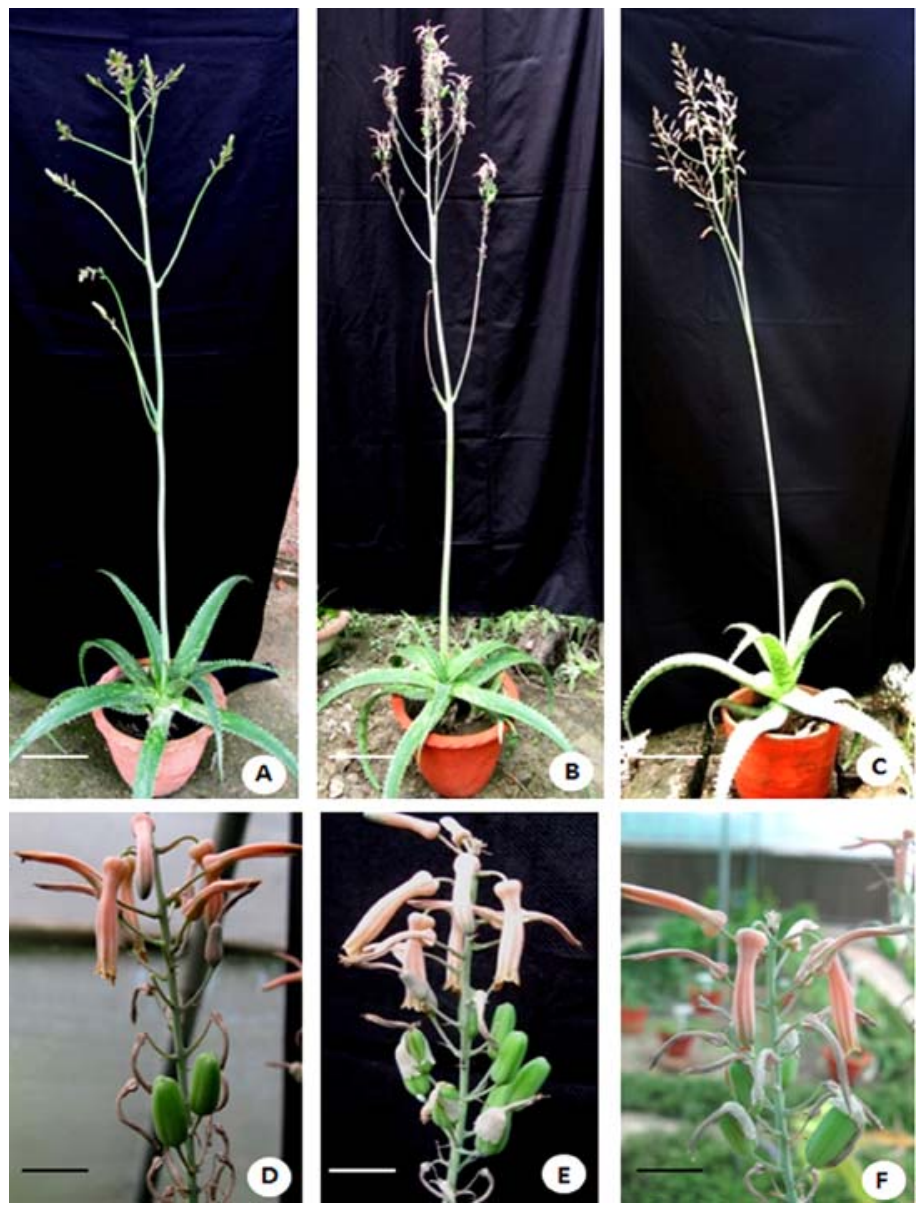

Fig. 2. Flowering and formation of fruits and seeds in the Aloe vera (a-c) Aloe vera somaclones showing inflorescence in the first, second and third year of flowering, respectively. Bar $=8.0 \mathrm{~cm}$. (d-f) Maturation of inflorescence with flowers and settings of fruits in three successive years. $B a r=8.0 \mathrm{~cm}$.

that the somaclones produced varied number of fruits with viable, fertile seeds through non-transformed method. Somaclonal variation provides a valuable source of genetic variation for the improvement of crops through the selection of novel variants, which may show resistance to disease, improved agronomic quality, or higher yield. Since, propagation by means of sexual reproduction through seeds is very rare in Aloe vera, viable seed production in Aloe may facilitate undertaking different genetic improvement programs. 
Cultivated Aloe species produces bisexual flowers and their microspores are produced through regular meiosis but no one has yet reported any form of seed setting (viable or nonviable, mature or immature) in any cultivar of this species. Velásquez-Arenas et al. (2008) reported the floral phenology of Aloe vera and Aloe saponaria, where they observed $\sim 228$ yellow flowers on a long inflorescence axis with 1 - 3 shafts in Aloe vera. Although both of them flowered by the end of the flowering period, fruits were observed only in A. saponaria with $12 \%$ reproductive efficiency. Thus, propagation of Aloe vera solely depends on production of limited numbers $(4-5)$ of vegetative suckers per plant per year.

The average number of seeds obtained in somaclones was $\sim 400-480$ per plant per year. The data revealed from the observations during the first year showed that $\simeq 61 \%$ and $\simeq 22 \%$ seeds of un-dehisced and dehisced fruits, respectively, germinated under in vitro condition within 4 weeks (Table 3) (Fig. 3e-h). In the first year, seed germination in natural environment or in vivo condition was not achieved. But, in the second and third year, 25 and $28 \%$ seeds of dehisced mature fruits were germinated in in vivo condition (Fig. 3i, k). In the same year the percentage of seed germination increased to $70.58 \%$ in in vitro condition (Fig. 3j). The results point out to the fact that seeds isolated from green un-dehisced fruits have more potential for germination than completely mature seeds. Germinated plants were transferred to potted soil pots and kept in green house (Fig. 31).

A higher percentage of germination from green pods is beneficial as it will reduce the breeding cycle. Weitbrech et al. (2011) pointed out that early seed germination contributes to better seed and seedling performance and it is important for plant establishment in the natural and agricultural ecosystem. Although in vivo seed germination could not occur in the first year, in the second and third year $\sim 25 \%$ and $\sim 28 \%$ seeds of dehisced mature fruits germinated under in vivo condition.

Mitotic chromosomal analysis of donor plant and tissue culture raised plants of this cultivar showed diploid cells having $2 n=14$ chromosomes with bimodal karyotype (Fig. 4a). There were no anomalies in gross chromosome structure and organization of any of the regenerated plants. From meiotic chromosome analysis it has been observed that both the mother and tissue culture regenerates had a consistent haploid chromosome number of $n=7$ in meiotic metaphase. Different stages of meiosis including metaphase I (Fig. 4b) and II, anaphase I and II and telophase were found and no abnormalities were noted in any of the stages. Pollen mother cells were usually regular with predominant bivalent (II) pairing (Fig. 4c). This confirms the basic number $x=7$. Approximately, 96.5\% pollen viability was recorded in both the cases. 

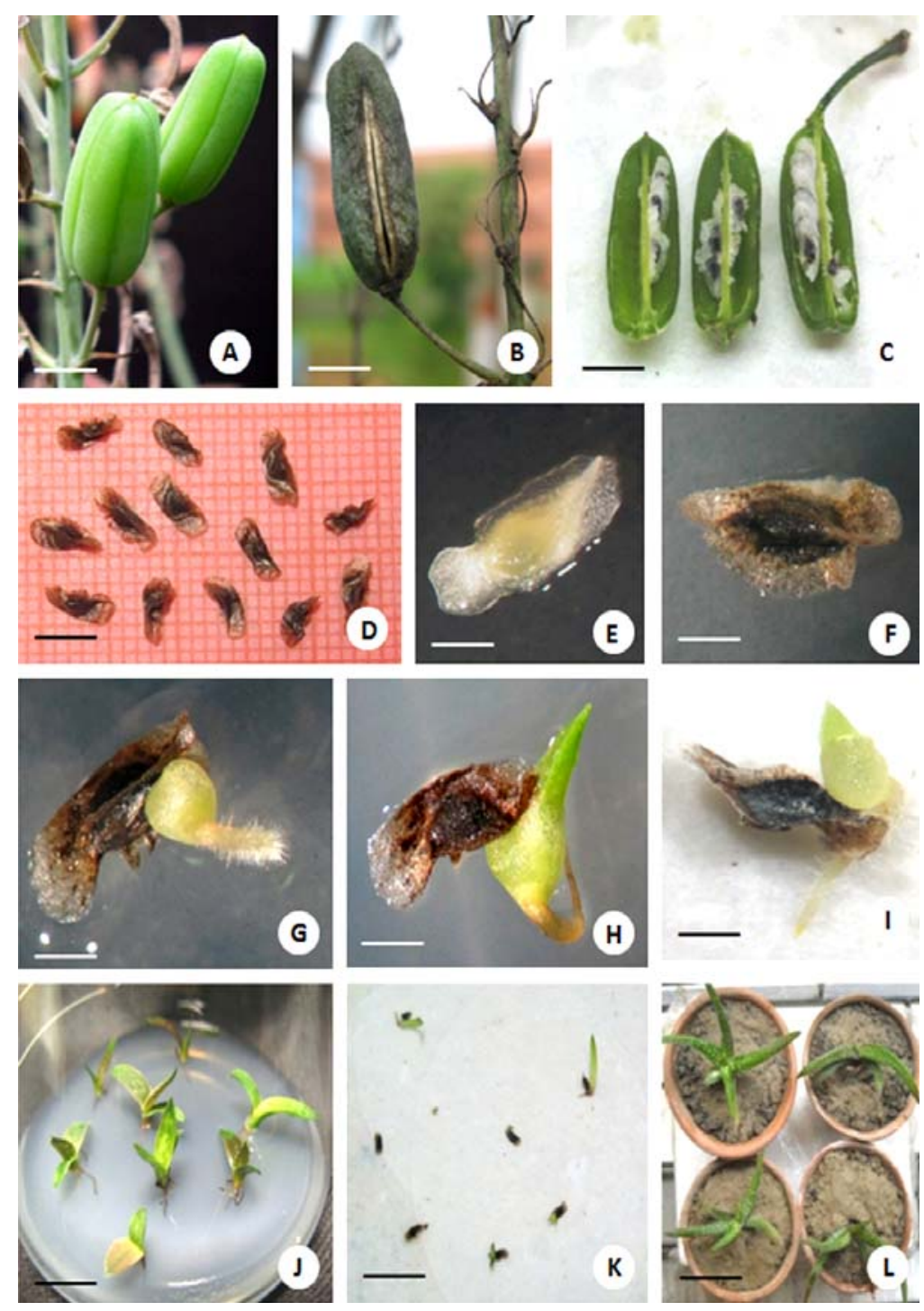

Fig. 3. Morphology of fruits and germination of seeds in Aloe vera (a) Green immature fruits of somaclone of A. vera. $B a r=2.0 \mathrm{~cm}$. (b) Mature fruit before dehiscence. Bar= 2.0 $\mathrm{cm}$ (c) Longitudinal section of fruit showing seeds. $B a r=2.0 \mathrm{~cm}$. (d) Isolated seeds from mature non-dehiscent green fruits of $A$. vera (e)-(h) Stages of seed germination in in vitro condition. Bar $=0.5 \mathrm{~cm}$. (i) In vivo germination of seeds. Bar $=0.5 \mathrm{~cm}$. (j-k) $R_{1}$ seedlings of somaclonal A. vera with two leaf stage. Bar $=0.5 \mathrm{~cm}$. (l) Seedlings growing in green house. Bar $=8.0 \mathrm{~cm}$.

Male sterility, a complex phenomenon is controlled either by cytoplasmic or nuclear genes which directly affects self compatibility, pollen viability. These results further cause failure in fertilization followed by lack of formation of fruits and seeds. In Aloe, male sterility and self-incompatibility have been reported 
earlier (Tie et al. 2004) and hardly any strategy has been reported so far, in the production of fertile seeds. Analysis of meiotic chromosomes in Aloe revealed that the mother plants could produce microspores through normal meiosis but they are incompetent to germinate, which is a prerequisite for fertilization and seed setting. While microspores of somaclone executing normal meiosis and pollen mitosis gained competency and participated in seed setting process. The competency factor has entered the reproductive cycle.

Table 3. Morphological characteristics of fruits of somaclone of Aloe vera

\begin{tabular}{lll}
\hline Characters & Data of 1st year & Data of 2nd year \\
\hline Colour of immature fruit & Light green & Light green \\
Colour of mature fruit & Dark green & Dark green \\
Number of fruits/inflorescence & $34.2 \pm 2.56^{\mathrm{d}}$ & $40.00 \pm 1.66^{\mathrm{c}}$ \\
Number of seeds/fruit & $12.00 \pm 0.12^{\mathrm{a}}$ & $12.00 \pm 0.12^{\mathrm{a}}$ \\
Time (days)needed for maturation of fruits & $15.06 \pm 1.98^{\mathrm{b}}$ & $15.06 \pm 1.98^{\mathrm{b}}$ \\
Seed germination percentage under in vivo condition & Nil & $25 \%$ \\
Seed germination percentage under in vitro condition & $61 \%$ & $70.58 \%$ \\
\hline
\end{tabular}

Each value represents the mean \pm S.E. Mean values having different letters in superscript are significantly different from each other $(\mathrm{P} \leq 0.05)$ according to DMRT (Wang et al. 2009).

RAPD analysis through DNA fingerprinting profiles of the somaclones (AvST1-I, AvST1-II, AvST1-IV) showed different banding patterns relative to the donor plant. As shown in Fig. 4d, the DNA fingerprinting profile generated with primer OPB 07 , two bands having molecular weight $700 \mathrm{bp}$ and $2 \mathrm{~kb}$ of the donor plant were absent in the profiles of the somaclones and germinating seeds. Again, RAPD profile generated with primer OPB 16 (Fig. 4e) revealed that one parental band of $650 \mathrm{bp}$ was absent in the profiles of somaclones and germinating seeds while three new bands with molecular weight 2 and $1.8 \mathrm{~kb}$ and $1.5 \mathrm{~kb}$ were generated in the profiles of somaclones, germinating seeds. Moreover, RAPD profile generated with primer OPB 18 (Fig. 4f) showed that two distinct bands of molecular weight $580 \mathrm{bp}$ and $1 \mathrm{~kb}$ in the profile of donor plant was absent in the profiles of somaclones and seed germinated plants. Thus, polymorphic bands in the DNA fingerprinting profiles of the donor and somaclones of AvS1 confirmed genetic difference among them which in turn provide important evidence of genetic basis of their morphological differences. 
Table 4. RAPD primers utilized for the assessment of in vitro raised plants of Aloe vera

\begin{tabular}{ccccc}
\hline Primers & $\begin{array}{c}\text { Sequence } \\
5 \rightarrow 3^{\prime}\end{array}$ & \% of GC & $\begin{array}{c}\text { Size range of } \\
\text { amplicons } \\
\text { (in Kb) }\end{array}$ & $\begin{array}{c}\text { Total no. of } \\
\text { amplicons }\end{array}$ \\
\hline OPA 07 & GAAACGGGTG & 60 & $0.2-1.5$ & 7 \\
OPB 01 & GTTTCGCTCC & 60 & $0.55-3.0$ & 6 \\
OPB 02 & TGATCCCTGG & 60 & $0.45-2.0$ & 7 \\
OPB 07 & GGTGACGCAG & 70 & $0.5-2.3$ & 4 \\
OPB 16 & TTTGCCCGGA & 60 & $0.6-2.0$ & 6 \\
OPB 18 & CCACAGCAGT & 60 & $0.25-1.5$ & 10 \\
OPD 01 & ACCGCGAAGG & 70 & $0.4-2.0$ & 9 \\
OPD 03 & GTCGCCGTCA & 70 & $0.48-2.8$ & 11 \\
OPD 05 & TGAGCGGACA & 60 & $0.6-3.0$ & 7 \\
OPM 02 & ACAACGCCTC & 60 & $0.5-2.0$ & 9 \\
OPM 04 & GGCGGTTGTC & 70 & $1.5-3.0$ & 5 \\
\hline
\end{tabular}

Table 5. Features of ITS1 sequences of tissue culture regenerated plants of Aloe vera

\begin{tabular}{lllll}
\hline Code & Description & $\begin{array}{l}\text { Accession no. } \\
\text { (ITS1) }\end{array}$ & $\begin{array}{l}\text { Average size } \\
\text { of ITS1 (bp) }\end{array}$ & $\begin{array}{l}\text { Average GC } \\
\text { \% of ITS1 }\end{array}$ \\
\hline AvST1-VI & Clonal plant & KP823453 & 321 & 59.2 \\
& & & & \\
AvST1-I & Seed setting somaclone & KP823447 & 321 & 58.57 \\
AvST1-II & Seed setting somaclone & KP823448 & 306 & 61.44 \\
AvST1-IV & Seed setting somaclone & KP823449 & 322 & 58.38 \\
AvST1-SdG1 & Seed germinated plant & KP823451 & 301 & 58.47 \\
AvST1-SdG2 & Seed germinated plant & KP823452 & 321 & 59.19 \\
\hline
\end{tabular}

The utility of RAPD technology for molecular analysis of in vitro regenerated plants has been documented by many workers (Hussain et al. 2008, Xing et al. 2010, Mohanty et al. 2011). RAPD analysis of Allium cepa showed a unique band in independent gametoclones which was proposed to have arisen due to a DNA sequence which was highly vulnerable to tissue culture-induced mutation (Bohance et al. 1995). Variations observed in total number of RAPD bands as well as the number of specific bands among the donor plant and somaclones of Aloe vera signify genetic differences of the genotypes due to tissue culture and induced somaclonal variation. 
Table 6. Details of changes in nucleotide in ITS1 sequence of AvST1-SdG1

\begin{tabular}{|c|c|c|}
\hline Population code & Type of nucleotide change & 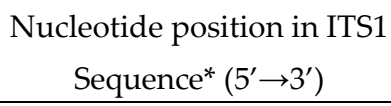 \\
\hline \multirow{7}{*}{ AvST1-SdG1 } & \multirow{7}{*}{$\begin{array}{l}\text { Single base } \\
\text { substitution }\end{array}$} & A190G \\
\hline & & G193A \\
\hline & & A194G \\
\hline & & C185A \\
\hline & & C186A \\
\hline & & C196G \\
\hline & & C481A \\
\hline
\end{tabular}

*Reference sequence is ITS sequence of AvS1 (donor plant)

ITS1 sequence data of donor and tissue culture regenerated plants of AvS1 revealed the average size of $\sim 320 \mathrm{bp}$. The PCR products were purified and sequenced, Fig. $4 \mathrm{~g}$ represents sequence chromatogram of 18S-ITS1-5.8S. Sequences have been submitted to NCBI database and accession numbers and $\%$ GC of those are tabulated in Table 5. The data showed that the length and \%GC of ITS1 sequences of all types of tissue culture regenerated plants of AvS1 were similar to that of the donor plant. Multiple sequence alignment of ITS1 sequences indicated that the somaclones and seed germinated AvS1 plants exhibited little divergence in the length and sequence of ITS1 with that of donor plant. In AvST1-SdG1 seed germinated plant, single nucleotide substitution occurred at 8 different nucleotide positions in ITS1 sequence (Table 6). Moreover, nucleotide substitutions occurred at 423rd base of AvST1-I and at 478th base of AvST1-IV. Like the donor plant, the conserved stretch (5'-GGCGCGATGGGCGCCAA GGAA-3') has also been found in ITS1 regions of all tissue culture regenerated plants of AvS1. ITS2 region showed conserved nature in the length and sequence among all in vivo and in vitro populations of Aloe vera. Conserved nature of ITS2 sequence has been reported earlier by several authors (Liu and Schardl 1994).

ITS1 sequence analysis of tissue culture regenerated plants of AvS1 showed overall similarity in length and sequence with that of the mother plant. Morphologically distinct 3 somaclones of AvS1 (AvST1-I, II, IV) showed very little divergence in ITS1 sequence data among them. We randomly selected germinating seedlings of AvST1-I and II and found ITS1 sequence of AvST1SdG1 (R1 plant) was slightly different from its R0 plant which is AvST1-I somaclone and also from the donor plant AvS1. Since, Aloe vera mainly reproduces by vegetative means and its gene flow is restricted due to male 
sterility and self-incompatibility, the seed setting somaclonal plants (R0) and seed germinated plants (R1) of Aloe vera in future may open a new window in the breeding program of this commercially important plant. Stable somaclonal variants variation of a specific type may be advantageous for the improvement of certain traits in breeding programs (Karp 1995, Jain 2001).
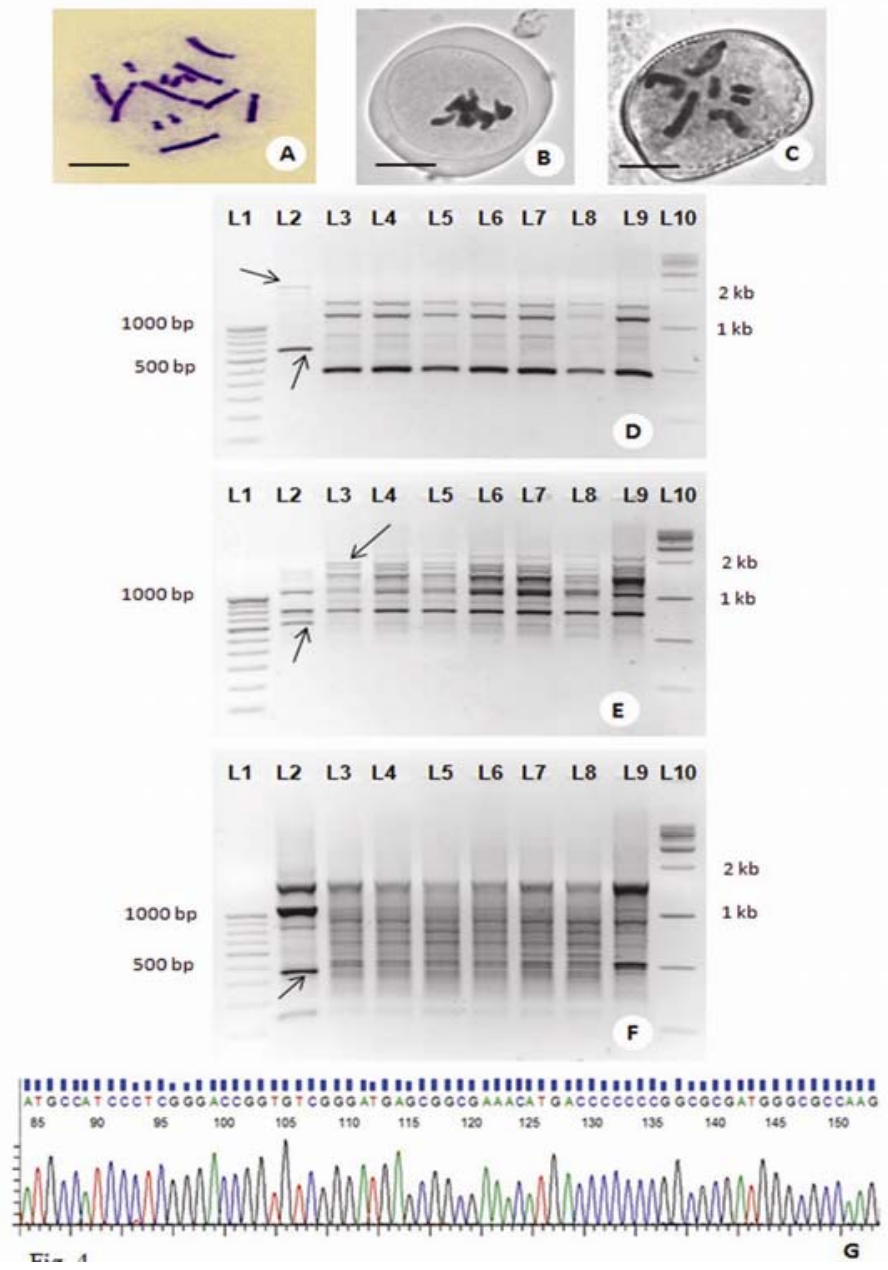

Fig. 4 Genetic studies of somaclonal Aloe vera (a) Mitotic metaphase of seed setting somaclones showing $2 \mathrm{n}=14$ bimodal chromosomes. Bar $=3 \mu \mathrm{M}$. (b) Meiotic metaphase I showing normal bivalents. Bar $=5 \mu \mathrm{M}$. (c) Pollen mitosis of donor A. vera plant showing distinct $\mathrm{n}=7$ bimodal chromosomes. Bar $=5 \mu \mathrm{M}$. (d)-(f) DNA fingerprinting profiles of donor and somaclones of Aloe vera generated with RAPD primer OPB 07, OPB 16 and OPB 18, respectively. Lane 1: 100 bp DNA ladder; lane 2: Donor plant; lane 3-5: Seed setting somaclones (AvST1-I, AvST1-II, AvST1-IV); lane 6-9: Seed germinated plants (g) Representative chromatogram of 18S-ITS1-5.8S partial nucleotide sequence of tissue culture regenerated plants of Aloe vera. 


\section{Acknowledgement}

Authors are grateful to Dr. Animesh Ghoroi for his help and encouragement in this study. They acknowledge their gratefulness to the Council of Scientific and Industrial Research (CSIR, India) for funding the project.

\section{References}

Aggarwal D and Barna KS (2004) Tissue culture propagation of elite plant of Aloe vera Linn. J. Biochem. Biotechnol. 13: 77-79.

Amoo SO, Aremu AO and Staden JV (2012) In vitro plant regeneration, secondary metabolite production and antioxidant activity of micropropagated Aloe arborescens Mill. Plant Cell Tiss. Org. Cult. 111: 345-358.

Banerjee D and Nandagopal K (2009) Phylogenetic analysis and in silico characterization of the GARS-AIRS-GART gene which codes for a tri-functional enzyme protein involved in de novo purine biosynthesis. Mol. Biotechnol. 42: 306-319.

Bohanec B, Jakše M, Ihan A and Javornik B (1995) Studies of gynogenesis in onion (Allium cepa L.): induction procedures and genetic analysis of regenerants. Plant Sci. 104: 215-224.

Chaudhuri RK, Pal A and Jha TB (2009) Regeneration and characterization of Swertia chirata Buch. Ham. Ex Wall. Plants from immature seed cultures. Scien. Horti. 120 :107-114.

Das A, Mukherjee P and Jha TB (2010a) High frequency micropropagation of Aloe vera L. Burm. f. as a low cost option towards commercialization. Plant Tissue Cult. Biotechnol. 20: 29-35.

Das A, Mukherjee P, Ghorai A and Jha TB (2010b) Comparative karyomorphological analyses of in vitro and in vivo grown plants of Aloe vera L. Burm. f. Nucleus 53(3): 8994.

Davis RH, Donato JJ, Hartman GM and Haas RC (1994) Anti-inflammatory and wound healing of growth substance in Aloe vera. J. Am. Podiat. Med. Assoc. 84: 77-81.

Davies RH, Leitner MG, Russo JM and Byrne ME (1989) Wound healing, Oral and topical activity of Aloe vera. J. Am. Podiat. Med. Assoc. 79: 559-562.

Davies RH, Stewart GI and Bregman PJ (1992) Aloe vera and the inflamed synovial pouch model. J. Am. Podiat. Med. Assoc. 82: 140-148.

Doyle JJ and Doyle JL (1990) A rapid total DNA preparation procedure for fresh plant tissue. Focus 12: 13-15.

Fukui K (1996) Plant chromosomes at mitosis. In: Fukui, K, Nakayama, S, eds. Plant Chromosomes; Laboratory Methods. Boca Raton, 1-18. FL: CRC Press

Garcia-Mas J, Oliver M, Gomez-Paniagua H and de Vicente MC (2000) Comparing AFLP, RAPD and RFLP markers for measuring genetic diversity in melon. Theor. Appl. Genet. 101: 860-864.

Grindlay D and Reynolds T (1986) The Aloe vera phenomenon: a review of the properties and modern uses of the leaf parenchyma gel. J. Ethno. Pharmacol. 16: 171-151. 
Hu Y, Xu J and Hu Q (2003) Evaluation of antioxidant potential of Aloe vera (Aloe barbadensis Mill.) extracts. J. Agri. Food. Chem. 51: 7788-7791.

Hussain Z, Tyagi RK, Sharma R, Agrawal A (2008) Genetic diversity in in vitro-conserved germplasm of Curcuma L. as revealed by RAPD markers. Biol. Planterum. 52: 627-633.

Jaljai NC, Sreenivasan TV, Pawar SM, Bhof PG and Garker RM (2006) Co 94012 - a new sugarcane variety through somaclonal variation. Sugar Technol. Rev. 8: 132-136.

Jain SM (2001) Tissue culture derived variation in crop improvement. Euphytica. 118: 53166.

Jha TB and Yamamoto M (2012) Application of EMA, Fluorescent Staining and FISH of rDNA in Analysis of Aloe vera L. Burm. f. Bull. Fac. Agri. Kagoshima. Univ. 62: 83-89.

Karp A (1995) Somaclonal variation as a tool for crop improvement. Euphytica. 85: 295302.

Larkin P and Scowcroft W (1981) Somaclonal variation a novel source of variability from cell cultures for plant improvement. Theo. Appl. Genet. 60: 197-214.

Liao Z, Chen MF, Sun Tan X and Tang K (2004) Micropropagation of endangered Chinese Aloe. Plant Cell Tissue Organ Cult. 76(1): 83-86.

Liu JS and Schardl CL (1994) A conserved sequence in internal transcribed spacer 1 of plant nuclear rRNA genes. Plant Mol Biol. 26: 775-778.

Minano HS, Gonzalez-Benito ME and Martin C (2009) Molecular characterization and analysis of somaclonal variation in chrysanthemum cultivars using RAPD markers. Sci. Hort. 122: 238-243.

Mohanty S, Panda MK, Sahoo S and Nayak S (2011) Micropropagation of Zingiber rubens and assessment of genetic stability through RAPD and ISSR markers. Biol. Plantarum. 55(1): 16-20.

Nia Y, Turner DK, Yatesa M and Tizard I (2004) Isolation and characterization of structural components of Aloe vera L. Leaf pulp. Int. Immunopharmacol. 4: 1745-1755.

Nei M, Li WH (1979) Mathematical model for studying genetic variation in terms of restriction endonucleases. Proc. Natl. Academy. Sci. 76: 5269-5273.

Rathore MS, Chikara J, Mastan SG, Rahman HK, Anand GV and Shekhawat NS (2011) Assessment of Genetic Stability and Instability of Tissue Culture-Propagated Plantlets of Aloe vera L. by RAPD and ISSR Markers. Appl. Biochem. Biotechnol. 165: 13561365.

Sharma AK and Sharma A (1980) Chromosome techniques - Theory and practice, third ed. Butterworths, London

Shelton RM (1991) Aloe vera, its chemical and therapeutic properties. Int. J. Dermatol. 30: 679-683.

Singh JP and Dhuria HS (1960) Studies on floral biology of sweet lime. Indian J. Horticult. 17: 9-20.

Strickland FM, Pelly RP and Kripke ML (1994) Prevention of ultraviolet radiationinduced suppression of contact and delayed hypersensitivity of Aloe barbadensis gel extract. J. Invest. Dermatol. 102: 197-204.

Tie J, Jin S, WU ZP and Bai HY (2004) Pollen viability and stigma receptivity of two species in Aloe. J. Jindongnan. Teachers. College. 2: 7-9. 
Velasquez-Arenaas R and Imery-Buiza J (2008) Reproductive phenology and floral anatomy of plants Aloe vera and Aloe saponaria (Aloaceae) in Cumana. Venezuela Revista de Biología Tropical. 56(3): 1109-1125.

Weitbrecht K, Muller K and Leubner-Metzger G (2011) First off the mark: early seed germination. J. Exp. Bot. 62: 3289-3309.

Wenping D, Shi D, Xu L, Yu G and Mili W (2004) A preliminary study on the induction and propagation of adventitious buds for Aloe vera L. Southeast China. J. Agri. Sci. 17(2): 224-227.

Williams JG, Kubelik AR, Livak KJ, Rafalski JA and Tingey SV (1990) DNA polymorphisms amplified by arbitrary primers are useful as genetic markers. Nucl. Acids. Res. 18(22): 6531- 6535.

Winters WD, Benavides R and Clouse WJ (1981) Effects of Aloe extracts on human normal and tumor cells in vitro. Econ. Bot. 35: 89-95.

Xing Y, Yu Y, Luo X, Zhang JN, Zhao B and Guo YD (2010) High efficiency organogenesis and analysis of genetic stability of the regenerants in Solanum melongena. Biol. Plantarum. 54(2): 231-236. 